\title{
AS CONTRADIÇÕES DA POLÍTICA DE SAÚdE NO BRASIL o Instituto Butantan
}

antonio Carlos Martins de Camargo

\begin{abstract}
Resumo: Este artigo pretende mostrar que a pesquisa científica, que há um século marcou as vidas de Adolfo Lutz, Oswaldo Cruz, Vital Brasil, Carlos Chagas e Rocha Lima, continua sendo a condição essencial para resolver problemas de saúde no Brasil. Optar por caminhos mais curtos, além de nos condenar ao subdesenvolvimento, consagra a contradição entre sermos capazes de elucidar o genoma de uma bactéria patogênica e continuarmos importando produtos e tecnologias e exportando, a fundo perdido, nossas riquezas e inovações. Palavras-chave: história da ciência; pesquisa; política científica.

Abstract: This article argues that scientific research, personified by figures such as Adolfo Lutz, Oswaldo Cruz, Vital Brasil, Carlos Chagas and Rocha Lima one hundred years ago, continues to be the single most important factor in resolving Brazil's public health problems. By seeking shortcuts, Brazil will not only condemn itself to a future of underdevelopment, but will also reinforce a perverse paradox: though we are capable of isolating the genome of a pathogenic bacteria, we continue to import products and technologies while we practice unrestrained enthusiasm in the exportation of our most precious material and scientific resources. Key words: history of science; research; science policy.
\end{abstract}

$\mathrm{O}$ homem levou milênios para deixar de ser um animal nômade, mas levou poucos séculos para se agrupar em vilas e cidades. Esse fenômeno assumiu proporções gigantescas após a revolução industri$\mathrm{al}$, dando origem às grandes cidades de hoje. Nessa trajetória humana, a população mundial passou de 5 milhões (neolítico) para mais de 5 bilhões nos dias de hoje. Esse fato relaciona-se a uma das características importantes das epidemias, isto é, à formação dos agrupamentos humanos em pequenas e grandes cidades à beira d'água. A água constitui não apenas o elemento essencial à vida, mas também o veículo da morte. Nas aglomerações humanas, a água, pela facilidade e rapidez em disseminar pragas e doenças, promove rapidamente suas propagações dizimando populações inteiras. Isso porque a mesma água que recebe os dejetos animais é utilizada pelo homem para beber e lavar.

Outros três aspectos que explicam as pragas humanas são: a mobilidade do homem e a conseqüente facilidade de propagação das doenças; a adaptação de microorganismos ao organismo humano por meio da migração de seu habitat natural para o homem, utilizando-se para isso diferentes vetores; e a rápida multiplicação dos microor- ganismos associada à sua grande variabilidade genética, natural ou induzida, o que torna quase infinitas as possibilidades de sobrevivência das espécies microbianas. Tais fatores são agravados pelas mudanças ambientais provocadas pelo homem, que causam desequilíbrios ecológicos, criando situações inusitadas para os microorganismos e resultando em freqüentes e alarmantes aparecimentos de novas doenças e epidemias. De 1951 até 1993, pelo menos 28 novas doenças infecciosas foram diagnosticadas como casos isolados ou surtos epidêmicos. Entre as mais conhecidas estão a dengue hemorrágica (1953), a doença de Lyme (1975), a Ébola (1976) e a Aids (1981). Nesse período, por outro lado, ressurgiram 14 doenças infecciosas até então contidas, que se tornaram mais disseminadas do que no passado, tais como cólera, câncer cervical, sífilis e tuberculose. É importante ressaltar que as mesmas razões que, no final do século XIX, motivaram a criação dos institutos de pesquisa, como o Instituto Pasteur em Paris, o Instituto Rockefeller nos Estados Unidos ou o Instituto Butantan (São Paulo) e o Instituto Manguinhos (Rio de Janeiro) no Brasil, continuam tão presentes quanto no passado. Este artigo pretende abordar as razões históricas que levaram à criação dos institutos e a evolução 
que sofreram por mais de um século, chamando a atenção dos governantes para a importância do papel que desempenham. A comparação da situação atual entre o Instituto Pasteur, na França, e o Instituto Butantan, no Brasil, poderá servir para mostrar o descompasso e a responsabilidade de nossos dirigentes quanto à necessidade de apoio ao desenvolvimento científico, fundamental para o bemestar da sociedade pelo benefício que proporciona à saúde pública.

\section{A DESCOBERTA DO MUNDO DOS MICRÓBIOS}

Pode-se dizer que a modernização da medicina começou no século XIX, quando alguns pesquisadores foram responsáveis por retirar a medicina das mãos das bruxas, dos curandeiros e dos alquimistas, transferindo-a para os pesquisadores científicos. Numa tentativa de refletir o panorama do século XIX, que conseguiu convencer desde o camponês até os imperadores da necessidade de apoio à pesquisa científica, procurar-se-á rever como alguns cientistas revolucionaram a medicina.

Simbolicamente, no dia $1^{\circ}$ de janeiro de 1801 , a corte de Weimar celebrava o nascimento de uma nova era. Como semelhante a Atenas, o hino Criação, de Haydn, coroava Goethe como Júpiter Olímpico, interpretando sua peça que abria um novo século. Em sintonia com esse espírito, a ciência alemã produziu cientistas que figuram entre os principais responsáveis pela modernização da medicina, como Jacob Henle (1809-1885), que, apesar da vida tumultuada por amores e pela atuação política (antagonismo a Bismarck e prisão em Berlin), revolucionou a anatomia e a patologia e descreveu, em termos modernos, que as doenças infecciosas eram causadas por microorganismos específicos. Sua profética visão das causas de doenças contagiosas, como a febre tifóide, a varíola e a escarlatina, antes mesmo de qualquer caracterização dos microorganismos, coloca-o como o criador da bacteriologia. Uma geração mais tarde, seu discípulo, Robert Koch (18431910), introduziu os métodos de fixação e coloração, permitindo visualizar e caracterizar bacilos. A despeito das grandes dificuldades financeiras, Koch pôde estudar medicina em Göttingen, onde Henle lecionava. Chegou a desaparecer da vida acadêmica por dez anos devido às condições adversas, mas continuou a pesquisar com o microscópio que ganhou de sua esposa, mantendo o trabalho até durante a guerra franco-prussiana, da qual participou como médico. Nesse período, Koch esclareceu a história completa da esporulação bacteriana e a etiologia do antrax. Após ingressar na vida acadêmica, acentuou sua contribuição à bacteriologia moderna, que não se restringiu à descoberta dos microorganismos causadores da tuberculose, da cólera e da doença do sono (tripanosomíase), contribuindo para o estabelecimento da abordagem experimental aplicada ao estudo das patologias causadas por microorganismos. Seus postulados, sua contribuição para o cultivo bacteriano e seu empenho na formação de discípulos marcaram o século XIX como o mais importante para a medicina moderna. Um de seus discípulos mais destacados foi o barão Shibasaburo Kitasato (1852-1931), o cientista japonês que descobriu o bacilo da peste bubônica.

Outro cientista alemão, Paul Ehrlich (1854-1915), fez descobertas que constituíram a base da quimioterapia e da imunidade. Como aluno, Ehrlich, que gostava de se divertir com corantes e vivia com a roupa manchada, levou ao desespero seus professores por seu aparente desinteresse pela química. Devido ao mau desempenho universitário, chegou a ser reprovado. Com seu temperamento casual, que preferia a tentativa e erro como método de investigação, pesquisava como se estivesse brincando. Sua imaginação, mais do que suas experiências com corantes, o levou a introduzir os arsenicais para o tratamento da sífilis. Fez descobertas fundamentais nos primórdios da imunologia, criando o famoso "dictum" do horror autotóxico, e lançou as bases do entendimento das doenças auto-imunes. Juntamente com Eli Metchnikoff (1845-1916), recebeu o prêmio Nobel em 1908. Esse último, grande cientista russo, viveu na prisão espiritual dos Romanoffs, o que o levou, por duas vezes, a tentar o suicídio. Só passou a dar vazão à própria genialidade quando se mudou para Messina, na Sicília, levando consigo a mulher com seus cinco irmãos e irmãs. Na Itália, Metchnikoff fez as observações que lhe permitiram descrever, pela primeira vez, o fenômeno da fagocitose, da mais alta importância na defesa imunológica.

A França também marcou o século XIX com contribuições científicas fundamentais para a microbiologia e o entendimento dos mecanismos das pragas que afligem o homem. O mais destacado cientista foi Louis Pasteur (1822-1895), cuja genialidade manifestou-se pelos seus múltiplos interesses e aptidões científicos e por dedicar-se à formação de seguidores que propagaram e lhe ampliaram as descobertas. Suas convicções e resultados experimentais contribuíram para banir crendices arraigadas na sociedade, como a da geração espontânea da vida, e estabeleceram com clareza a mu- 
dança dos antigos paradigmas que emperravam o desenvolvimento da ciência médica.

Filho de um curtidor de couro, Pasteur vivia na pequena cidade de Arbois, no interior da França. Ainda criança, ficou muito impressionado com a morte, por asfixia, de animais e homens mordidos por um lobo louco. Vários eminentes pesquisadores, como Magendie e Virchow, já haviam tentado explicar a causa da doença, sem consegui-lo. A dramática experiência de infância marcou Pasteur, motivando-o, mais tarde, a esclarecer a etiologia da raiva e a introduzir a prática da vacinação de cães para preveni-la.

Pasteur provou que os microorganismos atuavam nas fermentações de bebidas e alimentos e na preservação e melhoria de suas propriedades, fazendo a demonstração inequívoca da inexistência da geração espontânea. Suas descobertas tiveram um impacto muito além do interesse dessas pesquisas para a saúde pública, embora a prevenção e o tratamento de moléstias infecciosas fossem uma das suas mais importantes preocupações. Nesse contexto, Pasteur mostrou sua genialidade lançando as bases da imunoterapia preventiva e curativa, além de ter antecipado o advento dos antibióticos. A prática da vacinação aplicada à prevenção de epidemias em humanos e animais fez de Louis Pasteur um dos cientistas que, individualmente, mais contribuiu para o bem-estar do homem e o desenvolvimento da ciência médica.

O progresso da medicina no século XIX também deveu muito ao quaker escocês Joseph Lister (1827-1912), professor de medicina em Edinburgo, que introduziu a antisepcia na prática cirúrgica. Quando foi a Londres ensinar a importância dessa prática no Hospital St. John, foi ridicularizado e insultado por médicos, residentes e enfermeiras. Seu artigo "On the antiseptic principle in the pratice of surgery", publicado em 1867 na revista Lancet, marcou o início de uma verdadeira revolução na prática cirúrgica, ao descrever como se impedia que microorganismos causassem as infecções tão freqüentemente responsáveis pelo insucesso das intervenções.

Finalmente, a humanidade encontrara um caminho para se livrar das pragas e doenças causadas pelo inimigo invisível, os microorganismos. A admiração universal causada pelas novas descobertas científicas foi conseqüência direta das investigações científicas. Em decorrência desse fato, vultuosos investimentos foram feitos pelos governos e filantropos de vários países para a criação de institutos de pesquisa dedicados à aplicação da ciência em benefício da saúde pública. Gestos como o do Czar da Rússia, que doou uma condecoração de diamantes a Pasteur e dinheiro ao seu instituto, foram demonstrações do impacto causado por suas descobertas. No Brasil, os avanços da ciência médica também foram sentidos. O imperador Pedro II manifestou sua admiração pelo trabalho de Pasteur, doando uma grande soma ao Instituto Pasteur. Em retribuição ao gesto, colocou-se um busto do imperador brasileiro junto à biblioteca do Instituto Pasteur, em Paris.

\section{CRIAÇÃO DOS INSTITUTOS DE PESQUISA PARA O COMBATE Às PRAGAS DA HUMANIDADE}

Com a ajuda de uma subscrição internacional, iniciada em 1886, foi criado em 1888 o Instituto Pasteur, em Paris, dedicado ao estudo e ao tratamento da raiva e de outros problemas microbiológicos. A iniciativa desencadeou em todo mundo a criação de instituições com as mesmas finalidades. Nos Estados Unidos, por exemplo, Frederick T. Gates, assessor de John D. Rockefeller para assuntos filantrópicos, impressionado com o sucesso alcançado pela ciência médica européia, sugeriu, em 1897, a criação de um instituto de pesquisa com idênticas características. A decisão de Rockefeller de doar 200.000 dólares para a criação do Instituto Rockefeller, em New York, somente ocorreu em 1901, após a morte, aos três anos de idade, de seu primeiro neto, vítima de escarlatina. Segundo suas palavras, nem o melhor médico disponível na época teria condições de salvá-lo.

Curiosamente no Brasil daquele tempo, existiram homens, políticos e cientistas capazes de avaliar a importância que a pesquisa científica poderia ter para a saúde pública. Vivíamos na época da proclamação da República, abolição da escravatura, expansão da lavoura cafeeira e o início da industrialização dos Estados do Rio de Janeiro e de São Paulo. Esses fatores influíram na criação do Instituto Bacteriológico de São Paulo, que contribuiu para atrair e oferecer mais segurança aos imigrantes europeus quanto aos perigos do país pobre, de clima tropical, ainda considerado selvagem. Assim, em 18 de julho de 1892, Cerqueira Cezar, vice-presidente do Estado de São Paulo, e Vicente de Carvalho, secretário do Interior, criaram, por meio da Lei $\mathrm{n}^{\circ} 43$, o Instituto Bacteriológico. Inicialmente, a direção do Instituto ficou a cargo do biólogo francês Félix Le Dantec, indicado por Pasteur a pedido do embaixador Gabriel Piza, em 18 de março de 1893, sendo posteriormente substituído por Adolfo Lutz, bacteriologia e especialista em zoologia médica. 
Adolfo Lutz, nascido em 1855 no Rio de Janeiro, formou-se em medicina na Suíça. Desde cedo interessou-se pela pesquisa microbiológica. Sua contribuição à saúde pública brasileira foi extraordinária, graças às numerosas descobertas e realizações em benefício da saúde pública brasileira, bem como por ter sido responsável pelo incentivo à carreira de outros grandes pesquisadores brasileiros, como Vital Brasil e Oswaldo Cruz.

A história da criação do Instituto Butantan, em São Paulo, e do Instituto Manguinhos, no Rio de Janeiro, está intimamente ligada a um surto de peste bubônica e ao trabalho e à lucidez de Adolfo Lutz. Aproximava-se o final do século XIX quando, na cidade de Santos, irrompeu um surto epidêmico da praga, prontamente diagnosticada por Lutz e confirmada por pesquisadores do Instituto Pasteur, em Paris. Era preciso preparar o soro antipestoso, urgentemente. Em São Paulo, foi escolhida, como local ideal para instalação desse laboratório, a Fazenda Butantan, distante $10 \mathrm{~km}$ do centro da cidade e separada dela pelo rio Pinheiros, dando origem, mais tarde, ao Instituto Butantan, fortemente identificado com o Instituto Pasteur, na França. No Rio de Janeiro, a mesma situação originou o Instituto Manguinhos (atualmente Fundação Oswaldo Cruz ou Fiocruz). Para dirigir o Instituto Butantan, foi designado um médico ainda desconhecido, Vital Brasil Mineiro da Campanha, e para a direção do Instituto Manguinhos, escolheu-se o jovem médico Oswaldo Gonsalves Cruz, de 27 anos, recém-chegado do Instituto Pasteur, de Paris.

Um fato distinguiu, desde o início, o Instituto Butantan do Instituto Manguinhos: a preocupação de Vital Brasil com a alta incidência de acidentes com animais venenosos, especialmente aqueles provocados por serpentes. Assim como Pasteur havia sido motivado pelas dramáticas conseqüências médicas da mordida do animal raivoso, Vital Brasil foi influenciado pelos efeitos, igualmente dramáticos, da "mordida" da serpente venenosa. Acidentes ofídicos, que levavam ao óbito milhares de pessoas e animais em todo o país, tinham, e ainda têm, uma relevância muito grande para a saúde pública num país agrícola, com fantástica biodiversidade. O envolvimento do Instituto Butantan com o estudo e o tratamento de acidentes ofídicos, que mais tarde estendeu-se aos acidentes com outros animais venenosos, passou a ser a segunda maior atribuição do instituto de pesquisa recém-criado. Dessa forma, serão abordadas separadamente as contribuições do Instituto Butantan no combate a duas pragas distintas: as molés- tias infecciosas causadas por microorganismos; e aquelas provocadas por animais peçonhentos.

\section{AS MOLÉSTIAS INFECCIOSAS E SUAS HISTÓRICAS CONTRADIÇÕES}

Criados na mesma época que o Instituto Pasteur e o Instituto Rockefeller, com a finalidade de pesquisar, prevenir e tratar moléstias provocadas por microorganismos, dois institutos de pesquisa brasileiros - o Butantan e o Manguinhos - não conseguiram acompanhar o desempenho de seus similares estrangeiros. A grande diferença devese à fragilidade do apoio à atividade científica, no Brasil, em conseqüência do atraso cultural, político e econômico. A deficiência de apoio tem dificultado que a pesquisa científica no Brasil constitua um importante motor de transformações e de benefícios sociais como os que ocorreram na França e nos Estados Unidos durante o século XX. As pesquisas científicas realizadas pelos Institutos Pasteur e Rockefeller trouxeram tantos e tão diversificados benefícios à sociedade que é muito difícil descrevê-los. Para se ter uma idéia da importância dessas instituições, basta mencionar que, até hoje, nada menos que oito cientistas do Instituto Pasteur e 20 do Instituto Rockefeller receberam o Prêmio Nobel pelos frutos do avanço que proporcionaram às ciências médicas e biológicas.

Mesmo com todas as deficiências, houve, no Brasil, um período heróico de memoráveis conquistas realizadas por cientistas como Adolfo Lutz, Oswaldo Cruz, Vital Brasil, Carlos Chagas, Rocha Lima e tantos outros. Entretanto, o atraso cultural e o poder das oligarquias dominantes condenaram as instituições que abrigavam tais pioneiros à subserviência política atrelada ao imediatismo, fatores incompatíveis com o caráter desses homens e a natureza dessas instituições. Após esse período, as instituições viveram episódios descontínuos de grande efervescência científica e tecnológica, graças à capacidade de resistir às numerosas crises internas e à perseverança de muitos de seus pesquisadores, alguns de prestígio internacional. $\mathrm{O}$ Instituto Manguinhos, mais que o Butantan, apesar de os dois terem as mesmas atribuições científicas e tecnológicas no que se refere a doenças infecciosas, permaneceu identificado com os ideais que justificaram a sua criação, isto é, a pesquisa científica aplicada ao combate às moléstias infecciosas.

Ao longo dos seus 100 anos de existência, o melhor desempenho do Instituto Manguinhos no combate às moléstias infecciosas pode ser atribuído ao maior apoio fi- 


\begin{tabular}{|c|c|c|c|}
\hline \multicolumn{4}{|c|}{$\begin{array}{l}\frac{\text { TABELA 1 }}{\text { Investimentos e Desempenho Científico e Tecnológico de }} \\
\text { Instituições Brasileiras na Área da Saúde e o Instituto Pasteur da França } \\
2000\end{array}$} \\
\hline Indicadores & $\begin{array}{l}\text { Instituto } \\
\text { Butantan }\end{array}$ & $\begin{array}{l}\text { Instituto } \\
\text { Manguinhos } \\
\text { Fiocruz }\end{array}$ & $\begin{array}{l}\text { Instituto } \\
\text { Pasteur } \\
\text { França }\end{array}$ \\
\hline $\begin{array}{l}\text { Recursos Orçamentários } \\
\text { (milhões U\$) }\end{array}$ & 8,8 & 115 & 48 \\
\hline $\begin{array}{l}\text { Recursos Extra-orçamentários } \\
\text { (milhões U\$) }\end{array}$ & (1) 6,5 & (1) 14 & (2) 144 \\
\hline Pessoal Total & 850 & 3.100 & 2.500 \\
\hline Pesquisadores & 157 & 620 & 1.025 \\
\hline Publicações (3) & 55 & 309 & 731 \\
\hline Número de Patentes Total & 8 & 51 & 330 \\
\hline
\end{tabular}

Fonte: Instituto Pasteur <www.pasteur.fr>; Instituto Manguinhos Fiocruz. Relatório Tundisi; Instituto Butantan; Mello (2000); Geopi/Unicamp.

(1) Recursos públicos

(2) Recursos privados

(3) Número de publicações científicas indexadas (ISI) em 2000.

nanceiro, à maior produção científica e de patentes e ao maior número de pesquisadores contratados para pesquisas nas áreas da microbiologia, imunologia, patologia, epidemiologia, entre outras disciplinas das ciências médicas e biológicas (Tabela 1).

O Instituto Butantan viveu quase um século às voltas com suas contradições, que se resumem no fato de ser um instituto de pesquisa que, na maior parte da existência, foi pressionado pelo Estado a produzir imunobiológicos para resolver problemas urgentes de saúde pública. A pressão criou uma situação inusitada dentro de uma instituição de pesquisa, ao considerar essencial a produção de soros e vacinas em detrimento da atividade de pesquisa científica. O embasamento dessa política de saúde, que ainda prevalece no Instituto Butantan, pode ser assim resumido: num país pobre e populoso, o governo prefere gastar seus parcos recursos para fabricar soros e vacinas, desde que o investimento financeiro necessário para sua produção local seja menor que o da obtenção desses produtos da iniciativa privada. Para situações emergenciais não haveria nada de errado com essa política se isto não implicasse a exclusão da pesquisa científica que fundamentou e ainda fundamenta a existência do Instituto Butantan e de todos os institutos de pesquisa em moléstias infecciosas em todo o mundo. É óbvio, mesmo para o leigo, que, agindo dessa forma, o custo real dos soros e vacinas passa a ser elevadíssimo, pois passa a ser feito à custa da condenação do país ao subdesenvolvimento, ini- bindo as inovações e desprezando tantos outros benefícios que só a pesquisa científica traria a toda sociedade a médio e longo prazos. $\mathrm{O}$ argumento de que a pesquisa científica deve ser feita nas universidades é totalmente descabido pelos mesmos motivos que justificam a manutenção da pesquisa no Instituto Pasteur e em todos institutos do gênero no mundo.

Boa parte do atraso no desenvolvimento científico nas áreas de imunologia e microbiologia do Instituto Butantan pode ser explicada por esse viés da política científica e tecnológica do governo. Esse fato pode ser observado pela leitura do relatório bienal 1998-1999, elaborado pelo Instituto Butantan, comparando-o à análise dos dados do Instituto Manguinhos e do Instituto Pasteur (dados obtidos pelo MedLine $<$ www.ncbi.nlm.nih.gov $>$ ). Ao contrário da produção científica de suas instituições irmãs, brasileira e francesa, dominada quase inteiramente pelas publicações de trabalhos em microbiologia e imunologia, no Instituto Butantan verifica-se que, no biênio 1998-99, apenas $12 \%$ correspondem a artigos relacionados à área de microbiologia e $5 \%$ à de imunologia. No mesmo período nenhuma patente foi depositada. Por outro lado, essa política do governo na área da saúde cria uma contradição dentro do próprio governo, que investe consideráveis recursos públicos na formação de cientistas e tecnólogos, cria e mantém laboratórios com alta sofisticação, se orgulha dos avanços conseguidos em biotecnologia e não utiliza esse potencial para a nossa verdadeira auto-suficiência.

A preferência pelo imediatismo tem quase um século de existência, tendo sido criticada inúmeras vezes ao longo da existência do Instituto Butantan. Já em 1913, o alemão Martin Ficker, que foi professor de Rocha Lima em Berlin e contratado para reerguer o Instituto, dizia: "nada é mais perigoso para o desenvolvimento das ciências da higiene do que a imitação. Não se pode pretender que as experiências de um país se apliquem mais ou menos diretamente a outro país; ao contrário, as ciências da higiene devem evoluir na localidade onde irão ser aplicadas".

Embora sejam injustificáveis as conseqüências que essa política governamental acarretou para o desenvolvimento da pesquisa em imunologia e microbiologia do Instituto Butantan, é forçoso reconhecer que trouxe também benefícios sociais em curto prazo, graças ao repasse de recursos do Estado, para o fim específico de produção de soros e vacinas. A criação da Fundação Butantan, em 1989, foi de grande importância para a modernização da produção de imunobiológicos. Como pagamento pelo fornecimento de soros e vacinas, verbas extra-orçamentárias são 
repassadas pelo Ministério da Saúde àquela Fundação, criando assim condições para a modernização das atividades de produção do Instituto Butantan. Graças ao enorme e competente esforço feito pelo Prof. Isaias Raw, nesses últimos anos, conseguiu-se um fantástico progresso na produção de imunobiológicos, beneficiando amplamente milhões de brasileiros. Assim, os recursos captados pela Fundação Butantan foram aplicados na instalação de modernos fermentadores que produzem as vacinas básicas contra as infecções conhecidas como difteria, pertussis, tétano, raiva, tuberculose (BCG) e hepatite $\mathrm{B}$. Tecnologias importadas e aqui adaptadas e aperfeiçoadas ou desenvolvidas pelo seu Laboratório de Biotecnologia foram responsáveis pela produção de cerca de $50 \%$ de todas as vacinas utilizadas no Brasil. ${ }^{1}$

Sabe-se que hoje, ainda mais do que na época da criação do Instituto Butantan, corremos sérios riscos pela adoção de importação de pacotes tecnológicos prontos para resolver problemas de saúde pública, pois freqüentemente aparecem novas moléstias infecciosas que só poderão ser identificadas por pesquisadores do próprio país. Muitas vezes a importação de tecnologia tem que ser adotada por razões indiscutíveis, como as que levaram à modernização da atividade de produção de soros e vacinas do Instituto Butantan. Entretanto, esse Instituto, como um dos maiores responsáveis pela produção de soros e vacinas do país, deveria ter seus alicerces plantados em laboratórios de pesquisa que pudessem acompanhar o fantástico progresso que tem ocorrido na imunologia e microbiologia. Esses laboratórios constituiriam a infra-estrutura necessária para identificação e caracterização de microorganismos patogênicos, mecanismos de transmissão e de virulência, desenvolvimento de novas vacinas (vacinas de DNA, transgênicas, etc.) e tantos outros conhecimentos essenciais. Essa foi a intenção dos pesquisadores pioneiros que criaram o Instituto Butantan e o Instituto Manguinhos há mais de um século e que, mais do que nunca, os justificam como as primeiras trincheiras de proteção da sociedade contra as velhas e novas doenças que afligem nossa população, como a dengue hemorrágica, a hepatite $\mathrm{C}$ e tantas outras.

\section{INSTITUTO BUTANTAN COMO LIDERANÇA MUNDIAL NO ESTUDO DE ANIMAIS PEÇONHENTOS E DE SUAS TOXINAS}

Se, por um lado, o Instituto Butantan teve um desenvolvimento científico muito irregular nas áreas de microbiologia e imunologia durante um século de exis- tência, o mesmo não pode ser dito de sua contribuição ao estudo dos animais peçonhentos e de suas toxinas. É surpreendente verificar que a falta de apoio financeiro do Estado, que afetou toda instituição, foi menos deletéria às atividades de pesquisa nas áreas de animais peçonhentos e suas toxinas. Ocorreu que, por mais de um século, foram acrescentados às riquíssimas coleções do Instituto Butantan novos espécimes de serpentes e artrópodes, atraindo pesquisadores de todo mundo. Assim, durante toda sua existência, o Instituto Butantan abrigou e/ou colaborou com pesquisadores brasileiros e estrangeiros de renome mundial, estudiosos da biologia dos animais peçonhentos e das aplicações biológicas e terapêuticas de suas toxinas. Dessa forma, tornou-se a Meca de todos os cientistas interessados na área. Até hoje, a área de toxinas animais e de animais peçonhentos é responsável por 70\% a $80 \%$ das publicações científicas indexadas do Instituto Butantan, sendo muitas delas publicadas em periódicos internacionais de grande prestígio. Utilizando toxinas animais, pesquisadores brasileiros e estrangeiros, em colaboração com pesquisadores do Instituto Butantan, deram contribuições de grande impacto às ciências biomédicas. Entre as mais importantes, podem ser citadas:

- isolamento, caracterização e cristalização da crotoxina, extraída do veneno crotálico por Karl H. Slotta e Heinz Fraenkel-Conrat (1936-1938). Foi uma das primeiras proteínas a ter tal grau de caracterização;

- descoberta da bradicinina por Mauricio da Rocha e Silva e Wilson Beraldo, com a participação de Gastão Rosenfeld, pesquisador do Instituto Butantan, em 1949, utilizando o veneno da Bothrops jararaca;

- isolamento, por Sergio H. Ferreira (1963-1967), aluno e colaborador de Rocha e Silva, do primeiro agente antihipertensivo obtido do veneno da Bothrops jararaca, a partir do qual foi desenvolvido, pelo laboratório farmacêutico americano Squibb, o captopril, uma das drogas mais utilizadas por hipertensos em todo mundo.

O prestígio nacional e internacional do Instituto Butantan na área de toxinas animais e de microorganismos foi decisivo para que a instituição fosse incumbida da tarefa de sediar um dos dez Centros de Pesquisa, Inovação e Difusão (Cepids) criados pela Fapesp. O projeto, que reúne laboratórios de outras instituições, como a USP, Unifesp, Unesp e Ipen, foi aprovado, em setembro de 2000, após uma rigorosa avaliação de cerca de 120 consultores nacionais e internacionais designados para examinarem 112 projetos concorrentes em todas as áreas do conheci- 
mento no Estado de São Paulo. O Centro de Toxinologia Aplicada (CAT/Cepid) deverá ter o apoio da Fapesp por até 11 anos, recebendo o investimento de mais de 1 milhão de dólares anuais para pesquisar toxinas animais e de microorganismos, difundir os conhecimentos e estabelecer parcerias com a iniciativa privada. Hoje o CAT, com a participação do Instituto Uniemp (Instituto Universidade-Empresa) e da Fapesp e em parceria com três indústrias farmacêuticas nacionais consorciadas, desenvolve projetos de aproveitamento da propriedade intelectual (patentes) de interesse médico-farmacêutico originados de suas pesquisas, visando o desenvolvimento de produtos, cuja comercialização poderá retornar benefícios financeiros às instituições e a seus pesquisadores.

\section{"PAPERS", PATENTES E PRODUTOS}

A natureza das instituições de pesquisa no século XX tornou os institutos de pesquisa mais ajustados a desenvolver o trinômio "papers", patentes e produtos do que as universidades. Nos países do Primeiro Mundo, institutos como o Pasteur, na França, Max Planck, na Alemanha, Rockefeller Institute for Medical Research, Massachusetts Institute of Technology (MIT) e o National Institutes of Health (NIH), nos Estados Unidos, constituem a interface natural entre o conhecimento científico e a transferência desse conhecimento à sociedade. Esses institutos têm mais vocação e agilidade do que as universidades para converter o conhecimento científico em produtos. Suas atividades, que exigem um vultuoso investimento de recursos, são financiadas apenas em parte pelo Estado. Os aportes financeiros do Estado ao Instituto Pasteur, por exemplo, correspondem a 31,4\%, sendo que o restante vem da venda de produtos e serviços, de parcerias com indústrias, e de outras fontes.

É inegável que, nas últimas décadas, o Brasil avançou significativamente na capacitação científica. $O$ fato possibilitou ao país passar das últimas posições na produção de conhecimento científico para a $17^{\mathrm{a}}$ colocação no cenário mundial. Entretanto, o significativo esforço traduzido em "papers" retorna poucos benefícios sociais e riquezas à sociedade. Ironicamente, a revelação de novos conhecimentos gerados com recursos públicos brasileiros e divulgados por meio de revistas internacionais é mais bem aproveitada pelos países do Primeiro Mundo. Um dos melhores exemplos, como já abordado anteriormente, é o do Captopril, derivado do veneno de jararaca e de pesquisa científica brasileira, que rende bilhões de dólares anuais às indústrias farmacêuticas multinacionais.
Para que o conhecimento científico produzido nos institutos e universidades possa gerar produto, várias ações complementares, derivadas de outros setores públicos e privados, deve pavimentar o longo caminho até a sua finalização. Esse caminho inclui a proteção da propriedade intelectual (patentes, licenciamento e comercialização), a engenharia do produto, e a segurança para sua introdução na sociedade. Nessa área, o Brasil possui numerosos "gaps" que inviabilizam a transformação do conhecimento em produto. Se não forem resolvidos esses "gaps", o Brasil se converterá, na melhor das hipóteses, em licenciador de patentes sem valor agregado.

Com o apoio da Fapesp, o CAT está procurando contribuir para converter suas pesquisas científicas em produtos. As toxinas de origem animal e de microorganismos constituem um riquíssimo manancial de substâncias derivadas da biodiversidade brasileira. Essas moléculas são fármacos potenciais de grande interesse científico. Contudo, para tirar o melhor proveito desse cobiçado patrimônio da natureza, não basta fazer pesquisa científica de alta qualidade. É necessário atuar com eficiência na proteção da propriedade intelectual, não apenas patenteando invenções como também agregando valor às descobertas que vêm sendo feitas no Instituto ou em laboratórios de instituições associadas. Nesse sentido, o CAT/Cepid, o Uniemp e um consórcio de indústrias farmacêuticas nacionais (Coinfar) estão empenhados na criação de uma agência de gestão de inovação (AGI) na área farmacêutica, que deverá intermediar as ações necessárias à conversão de patentes em produtos. A agência, que deverá receber o apoio da Fapesp, reunirá especialistas nas áreas de direito à propriedade intelectual, de inteligência competitiva, de captação de recursos e de negociação com investidores e industriais da área farmacêutica. Por outro lado, a instalação da agência é condição imprescindível, mas não basta. Para que se agregue valor a um potencial produto farmacêutico, é necessário adquirir competência visando o desenvolvimento do produto. Isso compreende produzir novas moléculas a partir do protótipo natural (toxina), com propriedades farmacodinâmicas mais adequadas, pesquisar a melhor formulação farmacêutica e efetuar os ensaios pré-clínicos e clínicos. Todos esses passos exigirão um esforço conjunto de instituições públicas, indústrias, recursos de fomento e órgãos financiadores, que induzam a implementação de programas criativos.

Parece que finalmente o Brasil começa a despertar para a urgência de adequar suas estruturas ao aproveitamento de seu imenso potencial de recursos naturais e humanos. 
Há fortes indícios, tanto por parte do governo quanto da iniciativa privada de capital nacional, de que se está procurando aparar arestas para que o esforço feito pelos pesquisadores científicos brasileiros contribua efetivamente ao desenvolvimento social e econômico do país. Vários fatores contribuem para uma perspectiva mais otimista, entre os quais estão a lei de inovação que tramita no Congresso Nacional, a designação de recursos financeiros federais específicos de apoio às inovações, estimulando a sinergia entre a indústria e as instituições de pesquisa, a implementação de projetos como os Cepids da Fapesp, a Conferência Nacional de avaliação do potencial e das tendências para o melhor aproveitamento da C\&T brasileira, encomendada pelo Ministério da Ciência e Tecnologia e a crescente convicção de amplos setores da sociedade de que no mundo globalizado não há outra alternativa, se realmente quisermos sair do subdesenvolvimento.

\section{CUSTOS FINANCEIROS E MODELOS DE GESTÃO}

Os dados da Tabela 1 mostram que o Estado de São Paulo, que possui cerca de $2 / 3$ do número de habitantes da França, investe no seu principal instituto de mesma finalidade social que o Instituto Pasteur cerca de 12 vezes menos. No Brasil, o Estado continua sendo o único provedor dos recursos dos Institutos Butantan e Manguinhos. Uma das justificativas para isso é que somos uma sociedade pobre e sujeita a inúmeras pragas agravadas pelas precárias condições de educação, higiene e saneamento.

Na França, cerca de $68 \%$ desses recursos são provenientes da iniciativa privada. Em outros países do Primeiro Mundo, as instituições desse gênero, há muito tempo, se associaram à iniciativa privada para obtenção de recursos extra-orçamentários. A experiência de outros países tem mostrado que essa parceria não só é benéfica para desonerar o Estado, como também acrescenta parâmetros internacionais de qualidade e competitividade na produção científica e tecnológica. Esse modelo é empregado até mesmo em países com alta sensibilidade social, como na França, por exemplo.

Não se sabe se dotar o Instituto Butantan de uma estrutura semelhante à que existe no Instituto Pasteur, na França, iria ajustá-lo melhor às necessidades da saúde pública do Estado de São Paulo. Certamente não seria aplicável para o atendimento dos problemas das doenças órfãs, isto é, para aquelas que afetam a maioria da população sem condições financeiras para a prevenção ou o tratamento.
Para isso não devem faltar recursos públicos. Para todas as outras atividades do Instituto Butantan, há espaço para atração de investimentos privados.

No passado, as tentativas de introduzir as prerrogativas da iniciativa privada no Instituto Butantan fracassaram. Uma das mais antigas foi a de Arthur Neiva, em 1917. Contudo, a estrutura da instituição era, e continua sendo, incompatível com o sistema de parceria e mais ainda com a venda direta de serviços e produtos.

É importante, entretanto, que se diga que aumentar simplesmente o investimento do Estado no Instituto Butantan, embora necessário, está longe de ser suficiente. A estrutura da instituição precisa ser modificada para garantir que os benefícios sociais resultantes do aumento de investimentos não sejam comprometidos pelos interesses corporativos. Um dos aspectos estruturais que chama a atenção, sem que seja necessário aprofundar essa análise, é observar a distribuição dos recursos humanos do Instituto Butantan (Tabela 1). Verifica-se que os recursos humanos para a atividade-fim representam apenas $19 \%$ do total dos recursos humanos mantidos com verbas públicas. Há mais de cinco funcionários por pesquisador no Instituto Butantan, enquanto para o Instituto Pasteur essa relação é de pouco mais de dois funcionários por pesquisador. Este é um dado objetivo que ilustra uma das inúmeras distorções, que ao longo de muitas décadas foram se acumulando nessa instituição de pesquisa.

A busca de uma melhor adequação da estrutura do Instituto Butantan, visando desenvolver seu imenso potencial de contribuição social e econômico, seria a melhor forma de homenagear os grandes cientistas do passado que, direta ou indiretamente, deram origem a esse instituto. Não seriam mantidos apenas seus nomes nas ruas, nos museus e nas portas do prédio principal do Instituto Butantan, mas sim colocados seus exemplos de volta às bancadas dos laboratórios.

\section{NOTA}

1. Segundo dados da Fiocruz (Relatório Tundisi), essa Instituição produz $60 \%$ dos imunobiológicos utilizados no Brasil.

\section{REFERÊNCIAS BIBLIOGRÁFICAS}

BENCHIMOL, J.L. e TEIXEIRA, L.A. Cobras, lagartos e outros bichos. Rio de Janeiro, Editora UFRJ, 1993.

DE KRUIF, P. Microbe hunters. San Diego, Harcourt Brace and Co., 1926.

FONSECA, F. "Instituto Butantã. Sua origem, desenvolvimento e contribuição ao progresso de São Paulo". São Paulo em Quatro Séculos. São Paulo, Instituto Histórico e Geográfico de São 
Paulo. Comissão do IV Centenário da Cidade de São Paulo, v.2, 1954.

FUNDAÇÃO SEADE. São Paulo em Perspectiva. São Paulo, v.14, n. 3 , jul.-set. 2000.

GRUPO de Estudos sobre Organização da Pesquisa e da Inovação do Departamento de Política Científica e Tecnológica do Instituto de Geociências da Unicamp. Campinas, Komedi, 2000.

GUTHRIE, D. A History of Medicine. Londres, Edinburgh, Paris, Melbourne, Toronto e Nova York, Thomas Nelson and Sons Ltd., 1945.

HAGWOOD, B.J. Karl Heinrich Slotta (1985-1987) Biochemist: snakes, pregnancy and coffee. Toxicon, 39, 2001, p.1277-1282.

INSTITUTO PASTEUR. Disponível em: <http:\|www.pasteur.fr>.

KARLEN, A. Plague's progress, a social history of man and disease. Londres, Grã-Bretanha, Orion Books Ltd., 1995.

MELLO, D.L. Análise de processos de reorganização de institutos públicos de pesquisa do Estado de São Paulo. Tese de Doutorado. Campinas, Instituto de Geociências, Unicamp, 2000.
RELATÓRIO TUNDISI. Disponível em: $<$ http: \|www.mct.gov.br $>$.

ROBINSON, V. The story of medicine. Nova York, The New Home Library, 1943.

SECRETARIA DO ESTADO DA SAÚDE. Memórias do Instituto Butantan. Relatório Bienal. São Paulo, v.56, 1994/1995 e v.58, 1998-1999.

THE ROCKEFELLER UNIVERSITY. Achievements 1901-2001, a century of science for the benefit of humankind. Nova York, The Rockefeller Univesity Press.

Antonio Carlos Martins de Camargo: Médico, Professor da USP vice-diretor do Instituto de Ciências Biomédicas da USP. É atualmente diretor de Centro de Toxinologia Aplicada, um dos Centros de Pesquisa, Inovação e Difusão da Fapesp, co-autor do Livro Negro da USP. 